\title{
BMJ Open Reducing police occupational needle stick injury risk following an interactive training: the SHIELD cohort study in Mexico
}

\author{
Leo Beletsky, ${ }^{1,2}$ Daniela Abramovitz, ${ }^{1}$ Pieter Baker (D) , ,3 Jaime Arredondo, ${ }^{1,4}$ \\ Gudelia Rangel, ${ }^{5}$ Irina Artamonova, ${ }^{1}$ Phillip Marotta, ${ }^{6}$ Maria Luisa Mittal, ${ }^{1,7}$ \\ Teresita Rocha-Jimenéz, ${ }^{8}$ Mario Morales, ${ }^{1,9}$ Erika Clairgue, ${ }^{1}$ Sunyou Kang, ${ }^{2}$ \\ Arnulfo Banuelos, ${ }^{10}$ Javier Cepeda, ${ }^{1,11}$ Thomas A Patterson, ${ }^{12}$ \\ Steffanie A Strathdee ${ }^{1}$
}

To cite: Beletsky L, Abramovitz D, Baker P, et al. Reducing police occupational needle stick injury risk following an interactive training: the SHIELD cohort study in Mexico. BMJ Open 2021;11:e041629. doi:10.1136/ bmjopen-2020-041629

- Prepublication history and additional material for this paper is available online. To view these files, please visit the journal online (http://dx.doi.org/10. 1136/bmjopen-2020-041629).

Received 19 June 2020 Revised 20 March 2021 Accepted 22 March 2021

Check for updates

(C) Author(s) (or their employer(s)) 2021. Re-use permitted under CC BY-NC. No commercial re-use. See rights and permissions. Published by BMJ.

For numbered affiliations see end of article.

Correspondence to

Pieter Baker;

pabaker@health.ucsd.edu

\section{ABSTRACT}

Objective At a time of unprecedented attention to the public health impact of policing, it is imperative to understand the role of occupational safety in shaping officer behaviours. We assessed the longitudinal impact of police training in a quasi-experimental hybrid type-1 trial to reduce syringe-related occupational risk, while realigning police practices with public health prevention among people who inject drugs (PWID).

Setting Tijuana, Mexico.

Participants of 1806 Tijuana municipal police trainees, 771 reporting previous exposure to syringes were randomly selected for follow-up. All participants completed at least one follow-up visit; attrition at 24 months was $8 \%$. Intervention Between 2015 and 2016, officers received a training intervention (Safety and Health Integration in the Enforcement of Laws on Drugs, SHIELD) bundling occupational needle stick injury (NSI) prevention with health promotion among PWID.

Outcome measures Longitudinal analysis with generalised linear mixed models to evaluate training impact on occupational NSI risk via NSI incidence and prevalidated Syringe Threat and Injury Correlates (STIC) score. This composite indicator integrates five selfreported risky syringe-handling practices (eg, syringe confiscation, breaking) and was used as a proxy for NSI risk due to reporting bias and concerns about reliability of NSI incidence reports.

Results No change in self-reported NSI incidence was observed, but significant reductions in risk (16.2\% decrease in STIC score) occurred at 3 months, with a sustained decrease of $17.8 \%$ through 24 months, compared with pretraining $(p<0.001)$. Police assignment (patrol vs administration) moderated the training effect $(p=0.01)$. Younger age, male gender, lower rank and previous NSI were independently and significantly associated with higher NSI risk overtime, although all groups demonstrated significant reductions post-training. Conclusions SHIELD is the first intervention to be associated with significant sustained changes in police practices that pose risk for both occupational and the public's health. Integrating occupational safety and public
Strengths and limitations of this study

- Presents the first longitudinal analysis on police behavioural change resulting from a training intervention to reduce needle stick injury (NSI) and officer practices deleterious to public health.

- Uses municipal police officers as the primary unit of analysis of in a study of practices related to infectious disease.

- Reliability and reporting bias concerns deterred the use of NSI incidence as the study's primary outcome.

- Implements the previously validated Syringe Threat and Injury Correlates score in Iongitudinal evaluation, highlighting its utility in assessing occupational NSI risk among police.

- Situates police occupational safety as a critical consideration in designing public health interventions.

health education should inform other interventions to mitigate the community health detriments of policing behaviours.

Trial registration number NCT02444403.

\section{INTRODUCTION}

North America is in the grips of an unprecedented set of overlapping public health challenges, including the COVID-19 pandemic, historical burdens of problematic drug use, and police brutality. ${ }^{12}$ In the context of this upheaval, understanding the interface between police and public health has never been more urgent. A substantial and growing body of empirical literature enumerates the harms of abusive practices by police. ${ }^{3-6}$ Little is known, however, about how police occupational health concerns and stressors may shape officer behaviour. Recognising the role of policing as a structural driver of health outcomes also highlights the paucity 
of effective interventions that can sustainably modify policing practices deleterious to public health.

As a result of drug laws and other enforcement activities, police are at highly elevated risk of accidental needle stick injury (NSI). While injection drug use expands as a consequence of the North American overdose crisis, its incidence, prevalence and geographical distribution is also surging in Eastern and Central Europe, and East Africa. ${ }^{7}$ In virtually all of these jurisdictions, injection drug-related activities (drug possession and paraphernalia possession) remain criminalised. Although the actual risk of acquiring HIV and hepatitis through NSI is low, police officer NSI risk is among the highest of any other profession $^{8-12}$ and their perception of this risk is high. ${ }^{13}$ There are substantial institutional and cultural barriers to accurate reporting and prevention of NSIs, which negatively impact surveillance and response. ${ }^{14}$

Given the variety of health and safety exposures they experience, it is notable that police officers report high rates of stress and anxiety. ${ }^{15}$ Officer concern about NSI contributes to this toxic level of stress, where being stuck with a syringe ranks among the highest occupational concerns on par with bullet wounds. ${ }^{9}$ In the context of their drug law enforcement, police come into frequent contact with individuals at high risk for infectious diseases, including people who inject drugs (PWID), where concerns about occupational safety shape the character of such encounters. Police NSIs, their perceived risk and the sequelae of such phenomena have broader implications for their mental health, workforce capacity and community relations. ${ }^{9131617}$ While there is evidence linking use of force to stress and trauma among uniformed personnel, however, the current discourse on police brutality has largely ignored the role of occupational health and wellness as a driver of poor impulse control and violence.

Since police encounters are a known driver of health risk, it is no surprise that syringe-related enforcement practices also impact PWIDs' health. ${ }^{18-20}$ For example, arrest for syringe possession has been associated with HIV infection among PWID, syringe sharing, and utilising risky consumption spaces, such as shooting galleries. ${ }^{21-23}$ Extrajudicial syringe confiscations by police have been associated with HIV infection, syringe sharing and act as a barrier for PWID utilisation of syringe service programmes. $^{22} 2425$

In Mexico, consistent with many global locales, police typically receive no instruction on bloodborne pathogens or occupational NSI despite having contact with syringes in the field. In the USA, police officers may receive the National Institute for Occupational Safety and Health bloodborne pathogen training. ${ }^{26}$ However, this training does not typically cover NSI, let alone specific instruction for drug law enforcement practices. ${ }^{15}$ Police training programmes associated with Law Enforcement Assisted Diversion programmes have demonstrated promise in improving public health outcomes such as housing and employment, but do not address occupational safety risk. ${ }^{27} 28$ Broadly, police knowledge and practices related to syringe safety and related occupational safety issues linked to drug law enforcement remain low. ${ }^{2-32}$ In addition to a global dearth of training opportunities specific to bloodborne pathogen and occupational risk related to drug law enforcement, robust longitudinal evaluation of police trainings as interventions in benefit to public health is sparse. To our knowledge, the Safety and Health Integration in the Enforcement of Laws on Drugs (SHIELD) training model $^{33}$ is the first police training intervention and longitudinal cohort study of its kind.

We previously implemented police trainings in small evaluations using the SHIELD model in various global contexts. Findings based on preanalyses and postanalyses suggest training may have a positive impact with regards to attitudes towards addiction and people who use drugs, knowledge of HIV risk and drug policy, and intended behaviours related to handling syringes. ${ }^{8} 3034$ However, prior evaluations have not longitudinally assessed behavioural change among police or the behavioural impact on NSI risk over time following police training. To that end, we aimed to assess the longitudinal impact of the SHIELD police training intervention to reduce syringe-related occupational risk among officers in Tijuana, Mexico.

\section{METHODS}

\section{Intervention design}

Preliminary research using the SHIELD model lead to the development and implementation of Proyecto Escudo (Project SHIELD, in Spanish), a large police training intervention and quasi-experimental clinical trial (NCT02444403). ${ }^{33}$ This novel iteration of the SHIELD training model was implemented in Tijuana from 2015 to 2016 (follow-up through 2018) with the primary purpose of reducing occupational NSI risk. The training was developed in collaboration with the director of the municipal police academy and administered by police academy instructors using a train-the-trainer model. The training was implemented department-wide using a modified, stepped-wedge design as it was sequentially administered to clusters of officers. The occupational safety component of SHIELD covers policies and procedures for NSI prevention and response, with the aid of interactive and multimedia instructional techniques. ${ }^{30}$ SHIELD's instructional framework draws on the transcontextual model (TCM) ${ }^{35}$ to maximise internal motivation of police trainees. SHIELD accomplishes this by bundling occupational safety information with content on public health programmes and goals. This model emphasises officers' own concerns such as NSI to convey content that builds their knowledge, attitudes and practices in both the occupational safety and public health domains.

\section{Evaluation}

This study was designed to assess shifts in knowledge, attitude, behavioural change and NSIs over time. After training the entire Tijuana police department and 
administering surveys pretraining and post-training surveys to 1806 police officers, we followed a random subsample of 771 trainees with regular interview waves at $3,6,12,18$ and 24 months to assess intervention impact over time. This randomised subsample was selected among officers indicating (1) willingness to participate in 24 months of follow-up and (2) self-reported exposure to syringes in the 6 months prior to the training.

Evaluation consisted of self-administered surveys at pre, post and follow-up interview waves. At baseline, the survey collected sociodemographic characteristics as well as knowledge of syringe/drug policies and self-reported behaviours such as syringe-related practices that form the Syringe Threat and Injury Correlates (STIC) score. In addition, it measured attitudes, self-efficacy and knowledge factors (see online supplemental table S1 for additional details). Measures were based on prior research ${ }^{15}$ and piloting. ${ }^{36}$ All participants provided written informed consent.

\section{Outcome measure: NSI incidence}

The incident NSIs among police officers exposed to needles/syringes during the pretraining and post-training period, respectively, was the study's initial primary outcome of interest. To determine the incident NSIs for the pretraining period, in the baseline survey study participants who indicated having contact with needles/syringes were asked to report the number of NSIs sustained since the beginning of the Escudo training (ie, 28 February 2015) and the current date (ie, date of their pretraining survey). For those who sustained at least one NSI during the pretraining period, the time at risk was considered to be the time between the beginning of Escudo and the approximate date provided for the first NSI. If a date was not provided, then the event was assumed to have taken place mid-interval and the time at risk was calculated, accordingly. For those who did not sustain an NSI during the pretraining period, the time at risk was considered to be the length of their entire pretraining period (ie, time between the beginning of Escudo and the date they took the pretraining survey). Similarly, to determine the incident NSIs for the post-training period, at each follow-up visit (ie, 3, 6, 12, 18 and 24 months) study participants who indicated contact with needles, were asked to report the number of NSIs sustained since the previous visit. On the 3-month survey only, we also prompted participants for a repeat measure of their NSI experience pretraining to assess repeat test reliability. For participants who sustained at least one NSI during the post-training period, the time at risk was considered to be the time between the date of their pretraining survey and the date of their first NSI, which was assumed to have occurred at the midpoint between their last visit without an NSI and their first visit with an NSI. For participants who did not sustain an NSI during this period, the time at risk was considered to be the length of their entire post-training period (ie, between the date of their pretraining survey and the date of their last post-training survey). Notably, formative research within this cohort suggested reliability and measurement challenges with using self-reported NSI data as the primary outcome, including concerning levels of discrepancy between the test-retest measure of baseline NSI experience. Also, we found that prior to the training, knowledge of NSI and reporting procedures was low (online supplemental table S2).

\section{Outcome measure: STIC score}

To mitigate concerns surrounding inaccurate and inconsistent NSI reporting, we employed an additional surrogate measure-the previously-validated STIC score ${ }^{37}$ as an endpoint of interest. The STIC score, was established using the baseline (pretraining) SHIELD cohort in Tijuana and is detailed elsewhere. ${ }^{37}$ Briefly, this measure ranges from 1 to 4 , with a higher value indicating higher risk behaviour profiles of police. The STIC score has a very high level of internal consistency and provides an accurate and useful predictive value for NSI risk. The baseline Escudo cohort demonstrated a mode STIC score of 1.0, a mean (SD) of $2.0(0.8)$ and a median (IQR) of $2.0(1.2-2.6)$. In previous research, we found that the risk of experiencing an NSI was 2.4 times higher for every onepoint increase in STIC score value $(\mathrm{p}<0.0001) .{ }^{37}$ Since NSI incidence was the original endpoint for this longitudinal cohort study, we include additional information on this measure in this manuscript with online supplemental tables and figures. However, STIC score was treated as the primary endpoint for this analysis, including all multivariable modelling.

\section{Analytical methods: NSI incidence}

Pretraining and post-training incidence density rates of NSIs per 100 person-years were calculated by taking the ratio between the number of cases and the number of person-years at risk accumulated over the period of pretraining and post-training, respectively, and multiplying it by 100 . The corresponding $95 \%$ CIs were calculated using a Poisson distribution for the total sample and separately by gender, since male and female officers were significantly different with respect to many baseline characteristics. To evaluate the intervention effect on the incident NSIs, we first conducted univariate Poisson regression via generalised estimating equations with period (pretraining, post-training) as a within subject factor. An exchangeable correlation structure was assumed. Next, to identify additional covariates to control for, we conducted simple Poisson regressions with each potential covariate as a main effect while controlling for period. Interactions between period and each variable were assessed and either ruled out, if insignificant, or further evaluated, if significant at the 0.05 significance level. The variables that yielded $p \leq 0.10$ were considered as candidates for the multivariable model, but only the variables that retained their significance at 0.05 level were kept in the final multivariable model. In all the aforementioned regressions, training class was used as a covariate. Also, for the multivariable model, all the 
possible interactions between the variables included in the model were assessed and, depending on their significance, were either ruled out or further interpreted. Additionally, multicollinearity was assessed and ruled out on examining variance inflation factors and the largest condition indexes.

\section{Analytical methods: STIC Score}

To evaluate the training effect on the STIC score, we first used a univariate generalised linear mixed (GLM) model with the STIC score as the outcome variable with a lognormal distribution (ie, the mean STIC was modelled using a $\log$ link). Visit (visit 1 , visit $2, \ldots$, visit 6 ) was treated as the main fixed main effect. To control for within-class correlations as well as within-subject correlations, our modelling incorporated two random intercepts (subject level and class level) and a random slope for class.

All participants included in this analysis reported some level of exposure to syringes at baseline. We stratified our sample by work assignment (patrol vs non-patrol) as a proxy for exposure, with patrol assignees having a significantly higher likelihood of exposure to syringes/needles than non-patrol assignees. Wilcoxon rank sum tests were used to compare the two assignees groups with respect to continuous variables and $\chi^{2}$ or Fisher's exact tests were used to compare binary/categorical variables.

We identified the covariates to control for by conducting simple GLM regressions with the STIC score as the outcome and variables representing officers' characteristics as the main fixed effects. These variables include sociodemographic and police assignment details in addition to self-reported knowledge of drug policy and HIV epidemiology and attitudinal factors such as perceived supervisory support, selfefficacy, attitudes towards PWID and perceived subjective norms. These variables and their construction are described in detail in online supplemental table S1. We controlled for visit and assessed the interaction between visit and each variable. Variables that yielded $p \leq 0.10$ in the simple regressions were considered for inclusion as covariates in the final multivariable model. Only variables that retained a significance level $\leq 0.05$ (ie, gender (male vs female), assignment (patrol vs administrative/other), rank (higher than officer vs officer or lower), prior NSI (yes vs no)) were used as covariates in the final model. Lastly, we evaluated all possible interactions between the main effect (visit) and covariates, as well as all possible interactions between covariates. Only the interaction between visit and assignment was statistically significant and, consequently, retained in the final model and further evaluated by calculating and testing the simple effects of training among patrol and non-patrol assignees, respectively. We also graphed this interaction to illustrate the change in the STIC score over time for the two assignment groups. We conducted all statistical analyses using SAS V.9.4.

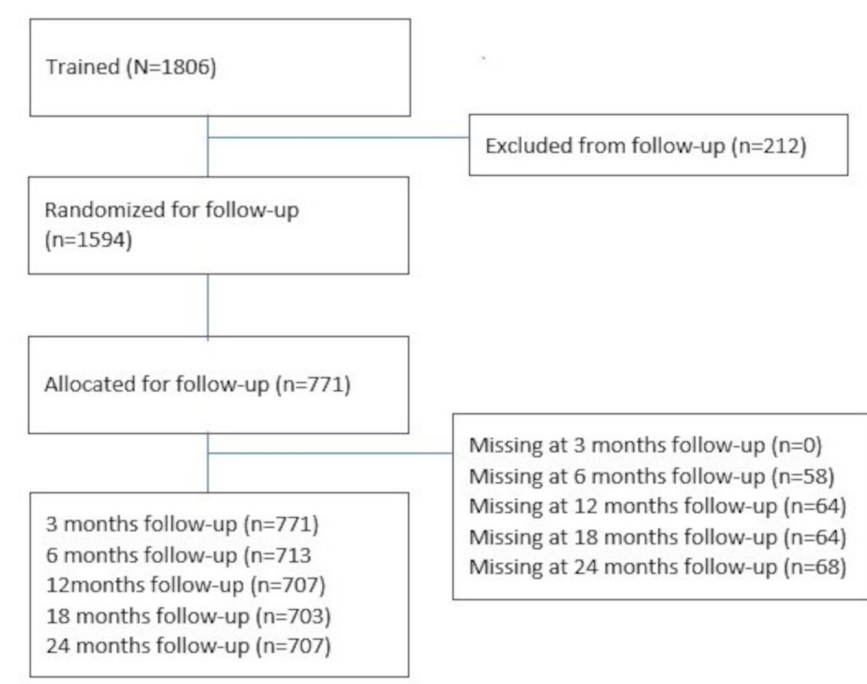

Figure 1 CONSORT diagram for participants trained, randomised for follow-up and analysed. CONSORT, Consolidated Standards of Reporting Trials.

\section{RESULTS}

Of the 1806 officers who completed the departmentwide training, a subset of 771 officers were randomly sampled and recruited into the study between February 2015 and May 2016 (figure 1). The entire cohort (100\%) completed at least one follow-up visit and attrition at 24 months was $8 \%$.

Among the 771 participants at baseline (table 1), $82.5 \%$ were male, $87.4 \%$ were patrol officers and $80 \%$ had attained a high school education or higher. The median age was 38 years (IQR: 33-43) and the median years of work experience was 11.2 (IQR: 8-18). All participants reported having contact with needles/syringes at least sometimes, with 33\% reporting frequent contact and $15.5 \%$ reporting that they had ever sustained an NSI while working in law enforcement. Patrol officers were significantly more likely than non-patrol officers to report frequent contact with needles/syringes $(36.3 \%$ vs $10.3 \% ; \mathrm{p}<0.001)$ and had a significantly higher median STIC score (median (IQR): 2 (1.4-2.6) vs 1 (1.0-2.0); $\mathrm{p}<0.001)$. However, patrol assignees did not differ significantly from non-patrol assignees with respect to reported lifetime NSIs.

\section{Longitudinal effects of the intervention on NSI incidence}

Among those at risk during the pretraining period (online supplemental table S3), there were 9 cases of NSI with an NSI incidence density of 1.48 per 100 personyears (PY) (95\% CI 0.51 to 2.44), whereas during the posttraining, among those at risk there were 32 cases, with an incidence density of NSIs of 2.54 per 100 PY (95\% CI 1.66 to 3.42). While the incidence density of NSIs post-training (vs pretraining) was higher among males, the reverse was true among females. More specifically, as shown in online supplemental table S4 and graphically depicted in online supplemental figure $\mathrm{S} 1$, a statistically significant interaction between period and gender was detected $(\mathrm{p}=0.017)$. 
Table 1 Trainee cohort characteristics at baseline by assignment status

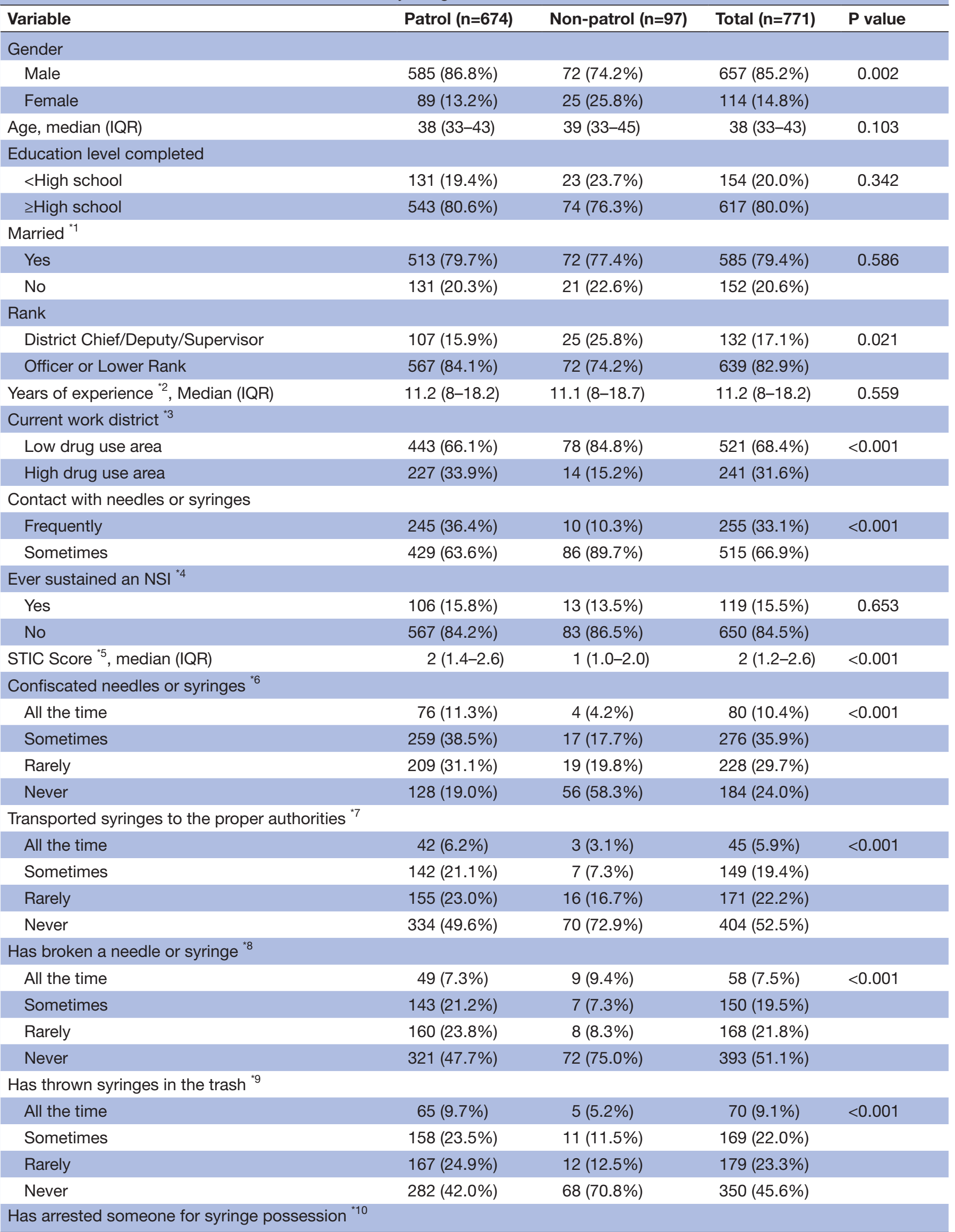




\begin{tabular}{|c|c|c|c|c|}
\hline Variable & Patrol $(n=674)$ & Non-patrol $(n=97)$ & Total $(n=771)$ & $P$ value \\
\hline All the time & $67(10.0 \%)$ & $2(2.1 \%)$ & $69(9.0 \%)$ & $<0.001$ \\
\hline Sometimes & $226(33.6 \%)$ & $13(13.5 \%)$ & $239(31.1 \%)$ & \\
\hline Rarely & $175(26.0 \%)$ & $9(9.4 \%)$ & $184(24.0 \%)$ & \\
\hline Never & $204(30.4 \%)$ & $72(75.0 \%)$ & $276(35.9 \%)$ & \\
\hline \multicolumn{5}{|l|}{ Frequency of physical altercations with drug users } \\
\hline All the time/sometimes & 304 (45.4\%) & 19 (19.8\%) & 323 (42.2\%) & $<0.001$ \\
\hline Rarely/never & $366(54.6 \%)$ & $77(80.2 \%)$ & $443(57.8 \%)$ & \\
\hline $\begin{array}{l}\text { Knowledge of HIV and hepatitis C transmission/ } \\
\text { prevention, median (IQR) }\end{array}$ & $3(2-4)$ & $3(2-4)$ & $3(2-4)$ & 0.833 \\
\hline Occupational NSI Knowledge, median (IQR) & $2(1-2)$ & $2(1-2)$ & $2(1-2)$ & 0.036 \\
\hline Attitudes on syringe access, median (IQR) & $0(0-1)$ & $0(0-1)$ & $0(0-1)$ & 0.366 \\
\hline Intended actions to prevent NSI, median (IQR) & $4(4-5)$ & $4(4-4)$ & $4(4-5)$ & 0.012 \\
\hline Stigma toward PWID ${ }^{* 12}$, median (IQR) & $4(4-4)$ & $4(4-4)$ & $4(4-4)$ & 0.634 \\
\hline \multicolumn{5}{|l|}{ Subjective norms of NSI prevention ${ }^{* 13}$} \\
\hline Yes & $455(67.7 \%)$ & $64(67.4 \%)$ & $519(67.7 \%)$ & 1.000 \\
\hline No & $217(32.3 \%)$ & $31(32.6 \%)$ & $248(32.3 \%)$ & \\
\hline \multicolumn{5}{|l|}{ Supervisory support for NSI prevention } \\
\hline Yes & $349(51.8 \%)$ & $58(59.8 \%)$ & $407(52.8 \%)$ & 0.158 \\
\hline No & $325(48.2 \%)$ & $39(40.2 \%)$ & $364(47.2 \%)$ & \\
\hline \multicolumn{5}{|l|}{ Supervisory support for NSI response ${ }^{* 14}$} \\
\hline Yes & $372(55.2 \%)$ & $53(55.2 \%)$ & $425(55.2 \%)$ & 1.000 \\
\hline No & $302(44.8 \%)$ & $43(44.8 \%)$ & $345(44.8 \%)$ & \\
\hline \multicolumn{5}{|l|}{ Self-efficacy to prevent NSI ${ }^{*} 15$} \\
\hline Median (IQR) & $8(7-10)$ & $8(7-10)$ & $8(7-10)$ & 0.673 \\
\hline \multicolumn{5}{|l|}{ Self-efficacy to respond to NSI ${ }^{* 16}$} \\
\hline Yes & $451(67.0 \%)$ & $62(66.0 \%)$ & $513(66.9 \%)$ & 0.907 \\
\hline No & 222 (33.0\%) & 32 (34.0\%) & 254 (33.1\%) & \\
\hline
\end{tabular}

*Missing observations $\left({ }^{* 1} \mathrm{n}=34 ;{ }^{*} \mathrm{n}=10 ;{ }^{*} \mathrm{n}=9 ;{ }^{* 4} \mathrm{n}=2 ;{ }^{*} \mathrm{n}=2 ;{ }^{*} \mathrm{n}=3 ;{ }^{*} \mathrm{n}=2 ;{ }^{* 8} \mathrm{n}=2 ;{ }^{91} \mathrm{n}=3 ;{ }^{*} \mathrm{n}=3 ;{ }^{* 11} \mathrm{n}=5 ;{ }^{*}{ }^{*} \mathrm{n}=1 ;{ }^{*} \mathrm{n}=4 ;{ }^{* 14} \mathrm{n}=1 ;{ }^{*} \mathrm{n}=1 ;{ }^{*} \mathrm{n}=4\right)$. NSI, needle stick injury; PWID, prevention among people who inject drugs; STIC, syringe threat and injury correlates.

Furthermore, based on the evaluation of simple effects of intervention by gender, for males the post-training (vs pretraining) incidence rate ratio (IRR) was 2.66 (95\% CI 0.56 to $12.7 ; \mathrm{p}=0.221)$ and for females the corresponding IRR was 0.28 (95\% CI 0.07 to $1.21 ; \mathrm{p}=0.088$ ).

Based on simple regressions controlled for period, officers who reported frequent physical altercations with drug users, officers who sustained NSIs previous to the Escudo study, and officers with a higher STIC score at baseline were significantly more likely to have a higher incidence rate of NSIs. Furthermore, based on the multivariable model (online supplemental table S5), officers with less work experience were at higher risk of incident NSIs (about 5\% increase per every 1 year less of experience; $\mathrm{p}=0.012$ ) and those who sustained an NSI prior to the beginning of Escudo had a seven times higher rate of incident NSIs $(p<0.001)$. In the multivariable model, the interaction between period and gender was also significant $(\mathrm{p}=0.014)$. However, likely due to lack of power, we were not able to detect significance in the simple effects of interaction by gender. We also identified wide inconsistency in NSI reporting. Comparing baseline and 3-month surveys, we found concerning levels of discrepancy between the test-retest measure of baseline NSI experience, with up to $14.2 \%$ of officers reporting divergent information about their NSI experience before the training.

\section{Longitudinal effects of the intervention on NSI risk (STIC Score)}

Overall, we found significant and sustained decreases in the STIC score representing risky occupational behaviours. According to our univariate GLM model (figure 2, table 2) the estimated marginal mean STIC score declined rapidly post-training and remained significantly lower at each follow-up visit. Specifically, the score 


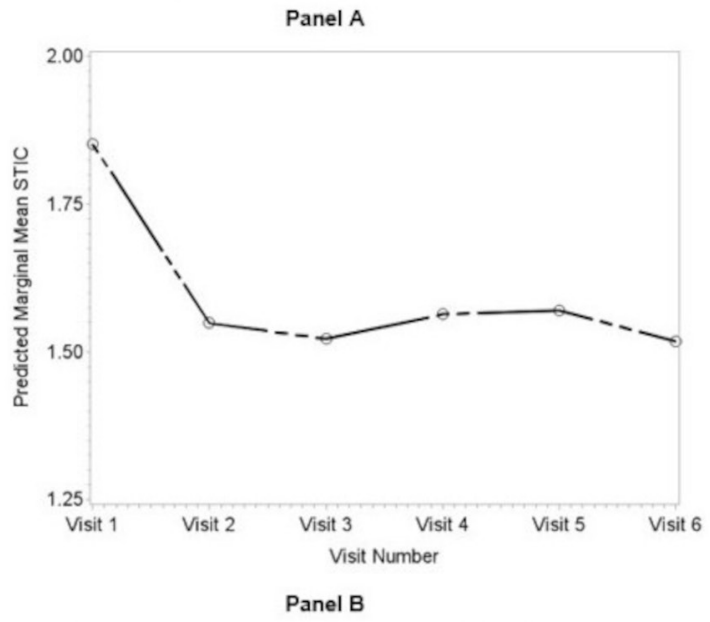

Interaction between visit and assignment (multivariable model)

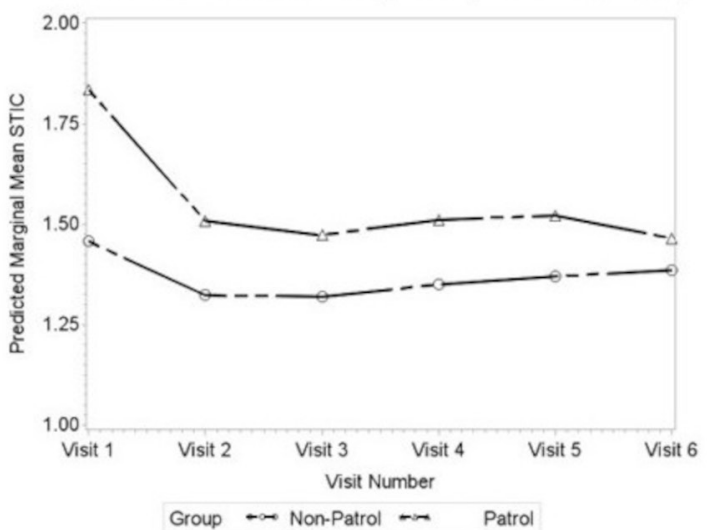

Figure 2 Training effect on the STIC score (univariate GLM model, Panel A). Interaction between visit and assignment (multivariable GLM model, Panel B). GLM, generalised linear mixed; STIC, Syringe Threat and Injury Correlates.

decreased by $16.2 \%$ at 3 months, a decrease still observed at the end of the study, with the score at 24 months being $17.8 \%$ lower than the score at pretraining. Simple associations between trainee cohort characteristics and STIC score are presented in table 3 .
Patrol Assignment as a moderator of training effects on STIC score

In multivariable analysis, patrol assignment moderated the training effect on the outcome as suggested by a significant interaction between visit and assignment $(\mathrm{p}=0.01)$ (table 4). At 3 months post-training, patrol assignees had a mean STIC score $18 \%$ lower than the corresponding score at pretraining (3-month mean $=1.51$ vs pretraining mean=1.83; $\mathrm{p}<0.001)$. This significant decrease was maintained at each follow-up visit. For non-patrol assignees, we also found a significant decrease in the STIC score (pretraining mean $=1.46$ vs 3 month mean $=1.32 ; \mathrm{p}=0.03$ ). However, this decrease $(8 \%)$ was about half of that observed among the patrol assignees (18\%). Furthermore, unlike the patrol assignees who sustained their decrease throughout the study, the non-patrol assignees started experiencing a waning effect after 6 months (figure 2B, table 4).

\section{Covariates independently associated with STIC score}

In addition to the significant training effect on the STIC score, the multivariable model (table 4) indicated that gender, rank, ever having an NSI, and age, were independently associated with the STIC score. Over the course of the study, compared with females, males had a $14 \%$ higher marginal mean STIC score (1.55 vs 1.36 ; $\mathrm{p}<0.001)$. This tendency began at pretraining, with males having a $12 \%$ higher STIC score than females (1.89 vs 1.68; $\mathrm{p}=0.005$ ) and was consistently observed throughout the study. Nevertheless, both males and females experienced significant declines in STIC scores and maintained these declines over time. Similarly, compared with those who reported never having sustained an NSI, those who did had an $8 \%$ higher marginal mean STIC score (1.51 vs $1.40 ; p=0.006)$. This difference was first observed at pretraining and sustained over 24 months. Conversely, the STIC score varied inversely with age, as evidenced by a $3 \%$ decrease per every 5 -year increase in age $(\mathrm{p}<0.001)$, and with rank, with those in a rank above officer having a $5 \%$ lower STIC score compared with those with a rank of officer or lower (1.41 vs $1.50 ; \mathrm{p}=0.04$ ).

In the simple GLM regressions, being male, having had prior NSIs, being a patrol assignee, working in high

\begin{tabular}{|c|c|c|c|c|c|c|}
\hline Main effect & Effect level & $\begin{array}{l}\text { Estimated LS } \\
\text { mean STIC }\end{array}$ & $\begin{array}{l}95 \% \mathrm{Cl} \text { for } \mathrm{LS} \\
\text { mean }\end{array}$ & Contrasts & $\begin{array}{l}95 \% \mathrm{Cl} \text { for } \\
\text { contrasts }\end{array}$ & $P$ value \\
\hline & 3 months & 1.55 & (1.50 to 1.60$)$ & 0.84 & (0.81 to 0.86$)$ & $<0.001$ \\
\hline & 6 months & 1.52 & (1.47 to 1.58$)$ & 0.82 & (0.80 to 0.85$)$ & $<0.001$ \\
\hline & 24 months & 1.52 & (1.47 to 1.57 ) & 0.82 & (0.79 to 0.85$)$ & $<0.001$ \\
\hline
\end{tabular}

Cls and $p$ values adjusted for multiple comparisons by using Bonferroni adjustment.

LS, Least Squares; STIC, Syringe Threat and Injury Correlates. 
Open access

Table 3 Simple* associations between trainee cohort characteristics and the STIC score

\begin{tabular}{|c|c|c|c|c|}
\hline Variable & Contrast & $\begin{array}{l}\text { Estimated } \\
\text { contrast in } \\
\text { mean STIC† }\end{array}$ & $95 \% \mathrm{Cl}$ & $P$ value \\
\hline Gender & Male vs female & 1.12 & (1.06 to 1.19$)$ & $<0.001$ \\
\hline Age & (per every 5 years) & 0.98 & (0.97 to 0.99$)$ & $<0.001$ \\
\hline Education sttainment & $\geq$ high school vs $<$ high school & 1.02 & (0.98 to 1.08$)$ & 0.333 \\
\hline Marital status & Married/common law vs not & 1.01 & (0.96 to 1.06$)$ & 0.636 \\
\hline Assignment & Patrol vs administrative & 1.14 & (1.10 to 1.19$)$ & $<0.001$ \\
\hline Rankł & $\begin{array}{l}\text { Officer or lower rank vs district } \\
\text { chief/deputy/supervisor }\end{array}$ & 0.93 & (0.88 to 0.99$)$ & 0.019 \\
\hline Years of experience & (per year) & 0.99 & (0.99 to 1.00$)$ & $<0.001$ \\
\hline Current work district *visitł & NA & NA & NA & $<.001 \S$ \\
\hline \multirow[t]{6}{*}{$\begin{array}{l}\text { Simple effect of current work } \\
\text { district by visit }\end{array}$} & $\begin{array}{l}\text { (High drug use area vs low drug use } \\
\text { area) } \\
\text { Pretraining }\end{array}$ & 1.21 & (1.14 to 1.28$)$ & $<0.001$ \\
\hline & 3 months & 1.21 & (1.14 to 1.28$)$ & $<0.001$ \\
\hline & 6 months & 1.15 & (1.08 to 1.22$)$ & $<0.001$ \\
\hline & 12 months & 1.16 & (1.07 to 1.22$)$ & $<0.001$ \\
\hline & 18 months & 1.12 & (1.05 to 1.19$)$ & $<0.001$ \\
\hline & 24 months & 1.31 & (1.24 to 1.39$)$ & $<0.001$ \\
\hline $\begin{array}{l}\text { Frequency of exposure to } \\
\text { needles*visitł }\end{array}$ & NA & NA & NA & $<.001 \S$ \\
\hline \multirow{7}{*}{$\begin{array}{l}\text { Simple effect of frequency of } \\
\text { exposure to needles by visit }\end{array}$} & (Frequently vs sometimes) & & & \\
\hline & Pretraining & 1.27 & (1.20 to 1.34$)$ & $<0.001$ \\
\hline & 3 months & 1.25 & (1.18 to 1.32$)$ & $<0.001$ \\
\hline & 6 months & 1.24 & (1.17 to 1.30$)$ & $<0.001$ \\
\hline & 12 months & 1.23 & (1.16 to 1.30$)$ & $<0.001$ \\
\hline & 18 months & 1.21 & (1.15 to 1.28$)$ & $<0.001$ \\
\hline & 24 months & 1.56 & (1.48 to 1.64$)$ & $<0.001$ \\
\hline $\begin{array}{l}\text { Frequency of physical altercations } \\
\text { with drug users*visitł }\end{array}$ & NA & NA & NA & $<.001 \S$ \\
\hline \multirow{7}{*}{$\begin{array}{l}\text { Simple effect of frequency of } \\
\text { physical altercations with drug } \\
\text { users by visit }\end{array}$} & $\begin{array}{l}\text { (All the times/sometimes vs rarely/ } \\
\text { never) }\end{array}$ & & & \\
\hline & Pretraining & 1.19 & (1.13 to 1.25$)$ & $<0.001$ \\
\hline & 3 months & 1.15 & (1.09 to 1.21$)$ & $<0.001$ \\
\hline & 6 months & 1.17 & (1.11 to 1.23$)$ & $<0.001$ \\
\hline & 12 months & 1.15 & (1.09 to 1.21$)$ & $<0.001$ \\
\hline & 18 months & 1.17 & (1.11 to 1.23$)$ & $<0.001$ \\
\hline & 24 months & 1.40 & (1.33 to 1.47$)$ & $<0.001$ \\
\hline Ever sustained an NSIł & yes vs no & 1.07 & (1.01 to 1.13$)$ & 0.014 \\
\hline ID knowledge index & (per qn. responded correctly) & 0.99 & (0.97 to 1.00$)$ & 0.019 \\
\hline Occupational NSI knowledge & (per qn. responded correctly) & 1.01 & (0.99 to 1.03 ) & 0.513 \\
\hline Law knowledge related to NSIs & (per qn. responded correctly) & 0.97 & (0.96 to 0.99$)$ & 0.002 \\
\hline Attitudes on syringe access & (per qn. responded correctly) & 0.95 & (0.94 to 0.96$)$ & $<0.001$ \\
\hline Intended actions to prevent NSI & (per qn. responded correctly) & 0.97 & (0.96 to 0.98$)$ & $<0.001$ \\
\hline Stigma towards PWID & (per one point increase in score) & 1.03 & (1.02 to 1.04$)$ & $<0.001$ \\
\hline
\end{tabular}




\begin{tabular}{|c|c|c|c|c|}
\hline Variable & Contrast & $\begin{array}{l}\text { Estimated } \\
\text { contrast in } \\
\text { mean STIC† }\end{array}$ & $95 \% \mathrm{Cl}$ & $P$ value \\
\hline Subjective norms of NSI prevention & Yes vs no & 1.05 & (1.03 to 1.08$)$ & $<0.001$ \\
\hline $\begin{array}{l}\text { Supervisory support for NSI } \\
\text { prevention }\end{array}$ & Yes vs no & 0.97 & (0.95 to 0.99$)$ & 0.013 \\
\hline Self-efficacy to prevent NSIs & (Per one point increase in score) & 0.99 & (0.98 to 1.00$)$ & 0.095 \\
\hline Self-efficacy to respond to NSIs & Yes vs no & 0.97 & (0.93 to 1.01$)$ & 0.118 \\
\hline
\end{tabular}

*Visit was used as a covariate in all analyses and the interaction between visit and each variable was assessed and either ruled out if not significant or retained in the model and simple effects calculated whenever significant. †The values represent the ratios of 2 means. $\ddagger$ Baseline variable.

§Value corresponding to F-test.

NA, not available; NSI, needle stick injury; STIC, Syringe Threat and Injury Correlates.

drug use areas, being frequently exposed to needles/ syringes, getting in frequent physical altercations with drug users, having stigmatising attitudes towards PWID and having higher subjective norms of NSI prevention were all predictive of higher STIC scores. Conversely, over the course of the study, being younger, ranking above an officer, having fewer years of experience, higher HIV and hepatitis $\mathrm{C}$ knowledge, higher law knowledge related to NSIs, better attitudes on syringe access, better intended actions to prevent NSIs, and better supervisory support for NSI prevention were predictive of lower STIC scores. We also found that the relationship between the STIC score and time following the training (visit number) was moderated by assigned work district, frequency of exposure to needles/syringes and frequency of physical altercations with PWID.

\section{DISCUSSION}

This study addressed several notable gaps in prior literature on occupational safety among law enforcement officers. Our analyses suggest that the SHIELD training had a significant and sustained impact on risky behaviours associated with NSI risk among police in Tijuana. We used a novel scale (the STIC score) to assess the longitudinal impact of a police training intervention on occupational NSI risk among police officers in Tijuana. Given concerns about the fidelity of self-reported NSI incidence and considering that NSI incidence was low, we cannot draw conclusions regarding the impact of the intervention on NSI incidence. However, our baseline measure of NSI $(15.8 \%)$ is consistent with prevalence data from previous police evaluations which range from $6.4 \%^{3}$ to 29.7\%. ${ }^{2}$ Additionally, we observed substantial and statistically significant reductions in the STIC score following the police training intervention. These changes persisted through 24 months of follow-up, indicating a promising potential for reducing the occupational risk of NSI among our police officer cohort.

While the impact was significant among all participants, males exhibited STIC score values that were steadily higher than females throughout the study period. This finding is consistent with previous literature on gender dynamics within this cohort suggesting that female officers are less likely to engage in risky behaviours such as confiscating syringes and extrajudicial arrests for syringe possession. ${ }^{38}$ This is further supported by a broader body of literature suggesting that female officers perform better than males on use of force and de-escalation metrics. $^{39-42}$

We also found that patrol assignment moderated the training effect on the outcome. In deploying training interventions to reduce occupational NSI, it is critical to consider the importance of patrol assignment and geography as an element of curricular design and tailoring.

Despite clear positive shifts in behaviours related to NSI risk, improvements at 24 months were by no means universal. This highlights opportunities for further refinement and improvement of the intervention. It also underscores the role of operational barriers and competing priorities, such as supervisory support and organisational incentives in shaping occupational risk and behaviours consistent with public health priorities.

There are several limitations to this study. First, we had originally planned to use NSI incidence as our primary outcome measure, but reliability and reporting bias concerns led us to formulate a reliable surrogate endpoint measure of occupational safety-the STIC score-in lieu of NSI incidence. Our experience underscores the need for fidelity and privacy of reporting systems for NSI and other occupational health issues in police agencies in addition to post-NSI medical aid and mental health services. Second, in our indeterminate findings on NSI incidence, the lack of power in detecting significant simple effects 
Table 4 Multivariate model for intervention effect on the STIC Score

\begin{tabular}{|c|c|c|c|c|c|c|}
\hline Main effects & Effect level & $\begin{array}{l}\text { Estimated } \\
\text { least sq } \\
\text { mean STIC }\end{array}$ & $\begin{array}{l}\text { Adj. } 95 \% \mathrm{Cl} \text { for LS } \\
\text { mean }\end{array}$ & $\begin{array}{l}\text { Adj. estimated } \\
\text { contrasts }\end{array}$ & $\begin{array}{l}\text { Adj. } 95 \% \mathrm{Cl} \\
\text { for contrasts }\end{array}$ & $P$ value \\
\hline \multirow[t]{6}{*}{ Visit } & Pretraining & 1.63 & (1.55 to 1.72 ) & Ref=pretraining & & \\
\hline & 3 months & 1.41 & (1.34 to 1.49$)$ & 0.86 & (0.81 to 0.92$)$ & $<0.001$ \\
\hline & 6 months & 1.39 & (1.31 to 1.48$)$ & 0.85 & (0.79 to 0.92$)$ & $<0.001$ \\
\hline & 12 months & 1.43 & (1.34 to 1.52$)$ & 0.87 & (0.81 to 0.94 ) & $<0.001$ \\
\hline & 18 months & 1.44 & (1.37 to 1.53$)$ & 0.88 & (0.83 to 0.94$)$ & $<0.001$ \\
\hline & 24 months & 1.42 & (1.35 to 1.51$)$ & 0.87 & (0.82 to 0.93 ) & $<0.001$ \\
\hline \multirow[t]{2}{*}{ Assignment } & Patrol & 1.55 & (1.48 to 1.13$)$ & 1.13 & (1.09 to 1.18 ) & $<0.001$ \\
\hline & Non-patrol & 1.37 & (1.29 to 1.44$)$ & Ref=non-patrol & & \\
\hline \multirow[t]{2}{*}{ Gender } & Male & 1.55 & (1.49 to 1.62$)$ & 1.14 & (1.08 to 1.20$)$ & $<0.001$ \\
\hline & Female & 1.36 & (1.28 to 1.45$)$ & Ref=female & & \\
\hline \multirow[t]{2}{*}{ Rank } & $>$ Officer & 1.41 & (1.33 to 1.50$)$ & 0.95 & (0.89 to 1.00$)$ & 0.043 \\
\hline & $\leq$ Officer & 1.50 & (1.44 to 1.56$)$ & Ref $=\leq$ officer & & \\
\hline \multirow[t]{2}{*}{ Ever sustained an NSI } & Yes & 1.51 & (1.42 to 1.60$)$ & 1.08 & (1.02 to 1.13$)$ & 0.006 \\
\hline & No & 1.40 & (1.35 to 1.46$)$ & Ref $=$ no & & \\
\hline Age (years) & Per every 5 years & NA & NA & 0.97 & (0.96 to 0.99 ) & $<0.001$ \\
\hline Visit $^{\star}$ assignment & & NA & NA & NA & NA & 0.012 \\
\hline \multicolumn{7}{|l|}{ Simple effects ${ }^{*}$} \\
\hline \multirow[t]{6}{*}{ Patrol } & Pretraining & 1.83 & (1.75 to 1.92$)$ & Ref=pretraining & & \\
\hline & 3 months & 1.51 & (1.44 to 1.58$)$ & 0.82 & (0.80 to 0.85 ) & $<0.001$ \\
\hline & 6 months & 1.47 & (1.41 to 1.54$)$ & 0.80 & (0.78 to 0.83 ) & $<0.001$ \\
\hline & 12 months & 1.51 & (1.44 to 1.58 ) & 0.82 & (0.80 to 0.85 ) & $<0.001$ \\
\hline & 18 months & 1.52 & (1.45 to 1.60$)$ & 0.83 & (0.80 to 0.86 ) & $<0.001$ \\
\hline & 24 Months & 1.46 & (1.40 to 1.53$)$ & 0.80 & (0.77 to 0.82 ) & $<0.001$ \\
\hline \multicolumn{7}{|l|}{ Non-patrol } \\
\hline & Pretraining & 1.46 & (1.36 to 1.56 ) & Ref=pretraining & & \\
\hline & 3 months & 1.32 & (1.22 to 1.43$)$ & 0.91 & (0.83 to 0.99 ) & 0.025 \\
\hline & 6 months & 1.32 & (1.20 to 1.46$)$ & 0.91 & (0.82 to 1.01$)$ & 0.062 \\
\hline & 12 months & 1.35 & (1.22 to 1.50$)$ & 0.93 & (0.83 to 1.03 ) & 0.172 \\
\hline & 18 months & 1.37 & (1.26 to 1.49 ) & 0.94 & (0.86 to 1.03 ) & 0.179 \\
\hline & 24 Months & 1.39 & (1.27 to 1.51$)$ & 0.95 & (0.87 to 1.04$)$ & 0.288 \\
\hline
\end{tabular}

Cls and $p$ values adjusted for multiple comparisons by using Bonferroni adjustment.

*The visit*assignment interaction was evaluated by calculating the simple effects of intervention for patrol and non-patrol trainees.

NA, not available; NSI, needle stick injury; STIC, Syringe Threat and Injury Correlates.

proved to be an issue. When completing our power calculations during the formative stage of the project, we did not anticipate a significant interaction between training period and gender, so we did not calculate the power for detecting the corresponding simple effects. Also, the original power calculations were based on the assumption of a pretraining NSI incidence of $5 \%$ and a corresponding post-training incidence of $4.25 \%$, whereas the observed pretraining incidence was far lower at $1.2 \%$. Thus, for the power calculations, we may have overestimated the reported pretraining NSI incidence. It is also possible that the actual incidence of NSIs was under-reported at pretraining stage, as we had hypothesised. Third, there is potential for under-reporting of component behaviours for the STIC score. However, use of self-administered surveys may have reduced social desirability bias. Fourth, participants were not randomised to training class as the intervention was conducted in concert with training schedules for the entire police academy. However, the follow-up cohort was randomly selected and we controlled for training class in the multivariable analysis. Fifth, selection bias may have been a concern as only officers who were willing to participate in the follow-up $(90 \%)$ were randomised and allocated for the longitudinal cohort. 
Finally, since all officers received the intervention, there is no true "control" arm and it may not be possible to infer the true intervention effect.

Despite its limitations, this study has several notable strengths. This is the first study to longitudinally assess police behaviour change, NSI risk and the impact of a large department-wide police training intervention. This is also the first prospective analysis of the STIC score, which demonstrates utility in assessing changes in occupational NSI risk among police. Our findings provide further rationale for expanded research, implementation and dissemination of police training using the SHIELD model.

In the future, adapted versions of the SHIELD model training may have particular relevance for protecting police officers and those they encounter in the context of the COVID-19 pandemic, since an increased risk of SARS-CoV-2 exposure among police has been reported. ${ }^{4344}$ Given the existing risk of bloodborne pathogen infection via occupational NSI, it is important to protect officers from elevated COVID-19 risk while they are tasked with enforcing public health measures. Police training to educate police on the epidemiology and prevention of SARS-CoV-2 infection, in additional to other tangible resources (eg, personal protective equipment, testing, prevention protocols, vaccines), may be necessary to protect front-line workers. A modified SHIELD model may also be an appropriate vehicle to address occupational safety concerns about fentanyl exposure, and other emerging occupational considerations. ${ }^{29} 45$

Our findings provide a solid rationale for the adaptation and testing of the SHIELD intervention in a US setting to address occupational safety and public health issues linked to drug-related harms. We are also conducting cost-effectiveness analyses based on these outcomes that will help to inform policy-makers and determine the value-for-money of police trainings on public health.

\section{Patient and public involvement}

Development of the intervention (including training materials), research questions and outcome measures took place in partnership with senior police staff (including study participants) and the office of the Secretaría de Seguridad Pública Municipal and Instituto de Capacitación y Adiestramiento Profesional. This manuscript (and others published by our team) were developed and disseminated (including coauthorship $(\mathrm{AB})$ ) in partnership with the Department of Planning and Special Projects, Secretaria de Seguridad Publica Municipal, Tijuana, Mexico.

\footnotetext{
Author affiliations

${ }^{1}$ School of Medicine, Division of Infectious Disease and Global Public Health,

University of California San Diego, La Jolla, California, USA

${ }^{2}$ School of Law, Bouvé College of Health Sciences, Northeastern University, Boston, Massachusetts, USA

${ }^{3}$ Graduate School of Public Health, San Diego State University, San Diego, California, USA
}

${ }^{4}$ Programa de Politica de Drogas, Centro de Investigacion y Docencia Economicas, Mexico, Mexico

${ }^{5}$ Mexico Section, U.S.-Mexico Border Health Commission, Tijuana, Mexico

${ }^{6}$ School of Medicine, Department of Psychiatry, Yale University, New Haven, Connecticut, USA

${ }^{7}$ School of Medicine, Universidad Xochicalco - Campus Tijuana, Tijuana, Mexico

${ }^{8}$ Society and Health Research Center, Facultad de Humanidades, Universidad Mayor, Santiago, Chile

${ }^{9}$ School of Government and Public Policy, University of Arizona Health Sciences Center, Tucson, Arizona, USA

${ }^{10}$ Department of Planning and Special Projects, Secretaria de Seguridad Publica Municipal, Tijuana, Mexico

${ }^{11}$ Department of Epidemiology, Johns Hopkins Bloomberg School of Public Health, Baltimore, MD, USA

${ }^{12}$ Department of Psychiatry, University of California San Diego, La Jolla, California, USA

Twitter Pieter Baker @pieterbaker

Acknowledgements Special thanks to the Secretaría de Seguridad Pública Municipal and Instituto de Capacitación y Adiestramiento Profesional (ICAP) in Tijuana for their continuous support and to our project field staff and participants for their hard work and commitment to this project.

Contributors LB and SAS conceived of the project. DA and IA conducted statistical analysis. EC oversaw field operations and data collection in Tijuana. LB and PB drafted the manuscript. PB, MM, AB, JA, SK, TR-J, GR, JC, PM, TAP and MLM contributed to the literature review, analytical interpretation and editing of the document. All authors contributed to the development of the manuscript.

Funding This work was supported by the National Institute on Drug Abuse [grant numbers R01DA039073, R37DA019829 and F31DA044794 (PI, Marotta), the Fogarty International Center of the National Institutes of Health (Award Numbers D43TW008633, R25TW009343, T32DA023356 and K01DA043421) and the UCSD Center for AIDS Research (CFAR) (International Pilot Grant NIAID 5P30AI036214), Open Society Foundations Latin America Program [grant numbers 0R2013-11352 and OR2014-18327.

Competing interests None declared.

Patient consent for publication Not required.

Ethics approval The study protocol was approved by UC San Diego and Universidad Xochicalco (Tijuana) institutional review boards.

Provenance and peer review Not commissioned; externally peer reviewed. Data availability statement Data are available on reasonable request.

Supplemental material This content has been supplied by the author(s). It has not been vetted by BMJ Publishing Group Limited (BMJ) and may not have been peer-reviewed. Any opinions or recommendations discussed are solely those of the author(s) and are not endorsed by BMJ. BMJ disclaims all liability and responsibility arising from any reliance placed on the content. Where the content includes any translated material, BMJ does not warrant the accuracy and reliability of the translations (including but not limited to local regulations, clinical guidelines, terminology, drug names and drug dosages), and is not responsible for any error and/or omissions arising from translation and adaptation or otherwise.

Open access This is an open access article distributed in accordance with the Creative Commons Attribution Non Commercial (CC BY-NC 4.0) license, which permits others to distribute, remix, adapt, build upon this work non-commercially, and license their derivative works on different terms, provided the original work is properly cited, appropriate credit is given, any changes made indicated, and the use is non-commercial. See: http://creativecommons.org/licenses/by-nc/4.0/.

ORCID iD

Pieter Baker http://orcid.org/0000-0002-2731-5470

\section{REFERENCES}

1 Friedman J, Beletsky L, Schriger DL. Overdose-Related cardiac arrests observed by emergency medical services during the US COVID-19 epidemic. JAMA Psychiatry 2020. doi:10.1001/ jamapsychiatry.2020.4218. [Epub ahead of print: 03 Dec 2020].

2 Cooper HLF. War on drugs policing and police brutality. Subst Use Misuse 2015;50:1188-94. 
3 Baker P, Beletsky L, Avalos L, et al. Policing practices and risk of HIV infection among people who inject drugs. Epidemiol Rev 2020;42:27-40.

4 Friedman J, Syvertsen JL, Bourgois P, et al. Intersectional structural vulnerability to abusive policing among people who inject drugs: a mixed methods assessment in California's central Valley. Int J Drug Policy 2021;87:102981.

5 West BS, Henry BF, Agah N, et al. Typologies and Correlates of Police Violence Against Female Sex Workers Who Inject Drugs at the México-United States Border: Limits of De Jure Decriminalization in Advancing Health and Human Rights. J Interpers Violence 2020:088626052097582. doi:10.1177/0886260520975820

6 Morales M, Rafful C, Baker P, et al. "Pick up anything that moves": a qualitative analysis of a police crackdown against people who use drugs in Tijuana, Mexico. Health Justice 2020:8:9.

7 Degenhardt L, Peacock A, Colledge S, et al. Global prevalence of injecting drug use and sociodemographic characteristics and prevalence of HIV, HBV, and HCV in people who inject drugs: a multistage systematic review. Lancet Glob Health 2017;5:e1192-207.

8 Beletsky L, Agrawal A, Moreau B, et al. Police training to align law enforcement and HIV prevention: preliminary evidence from the field. Am J Public Health 2011;101:2012-5.

9 Lorentz J, Hill L, Samimi B. Occupational needlestick injuries in a metropolitan police force. Am J Prev Med 2000;18:146-50.

10 Davis CS, Johnston J, de Saxe Zerden L, et al. Attitudes of North Carolina law enforcement officers toward syringe decriminalization. Drug Alcohol Depend 2014;144:265-9.

11 Cepeda JA, Beletsky L, Sawyer A, et al. Occupational safety in the age of the opioid crisis: needle stick injury among Baltimore police. $J$ Urban Health 2017;94:100-3.

12 de Perio MA, Victory KR, Groenewold MR. Needlestick injuries and other body substance exposures among police officers in a City police department. Am J Infect Control 2019;47:294-7.

13 Chitwood DD, McCoy CB, Inciardi JA, et al. HIV seropositivity of needles from shooting galleries in South Florida. Am J Public Health 1990;80:150-2.

14 Upjohn LM, Stuart RL, Korman TM, et al. New HIV diagnosis after occupational exposure screening: the importance of reporting needlestick injuries. Intern Med J 2012;42:202-4.

15 Beletsky L, Macalino GE, Burris S. Attitudes of police officers towards syringe access, occupational needle-sticks, and drug use: a qualitative study of one City police department in the United States. Int J Drug Policy 2005;16:267-74.

16 Cepeda JA, Strathdee SA, Arredondo J, et al. Assessing police officers' attitudes and legal knowledge on behaviors that impact HIV transmission among people who inject drugs. Int J Drug Policy 2017:50:56-63.

17 de Perio MA, Victory KR, Groenewold MR. Needlestick injuries and other body substance exposures among police officers in a city police department. Am J Infect Control 2019;47:294-7.

18 Beletsky L, Heller D, Jenness SM, et al. Syringe access, syringe sharing, and police encounters among people who inject drugs in New York City: a community-level perspective. Int J Drug Policy 2014;25:105-11.

19 Strathdee SA, Lozada R, Pollini RA, et al. Individual, social, and environmental influences associated with HIV infection among injection drug users in Tijuana, Mexico. J Acquir Immune Defic Syndr 2008:47:369-76.

20 Baker P, Beletsky L, Avalos L. Policing as a structural determinant of HIV risk among people who inject drugs: a systematic literature review. International Aids Society (IAS) 10th Conference on HIV Science, Mexico City, Mexico, 2019.

21 Pollini RA, Brouwer KC, Lozada RM, et al. Syringe possession arrests are associated with receptive syringe sharing in two Mexico-US border cities. Addiction 2008;103:101-8.

22 Booth RE, Dvoryak S, Sung-Joon M, et al. Law enforcement practices associated with HIV infection among injection drug users in Odessa, Ukraine. AIDS Behav 2013;17:2604-14.

23 Philbin M, Pollini RA, Ramos R, et al. Shooting gallery attendance among IDUs in Tijuana and Ciudad Juarez, Mexico: correlates, prevention opportunities, and the role of the environment. AIDS Behav 2008;12:552-60.

24 Strathdee SA, Lozada R, Martinez G, et al. Social and structural factors associated with HIV infection among female sex workers who inject drugs in the Mexico-US border region. PLoS One 2011;6:e19048.

25 Beletsky L, Lozada R, Gaines T, et al. Syringe confiscation as an HIV risk factor: the public health implications of arbitrary policing in Tijuana and Ciudad Juarez, Mexico. J Urban Health 2013;90:284-98.

26 de Perio MA. Evaluation of needlestick injuries and other exposures to bloodborne pathogens among officers in a City police department. contract No.: HHE report No. 2016-0121-3284. Cincinnati, OH U.S. Department of Health and Human Services, Centers for Disease Control and Prevention, National Institute for Occupational Safety and Health; 2017.

27 Clifasefi SL, Lonczak HS, Collins SE. Seattle's Law Enforcement Assisted Diversion (LEAD) Program. Crime \& Delinquency 2017;63:429-45.

28 Collins SE, Lonczak HS, Clifasefi SL. Seattle's law enforcement assisted diversion (lead): program effects on recidivism outcomes. Eval Program Plann 2017;64:49-56.

29 Winograd RP, Phillips S, Wood CA, et al. Training to reduce emergency responders' perceived overdose risk from contact with fentanyl: early evidence of success. Harm Reduct J 2020;17:58.

30 Arredondo J, Beletsky L, Baker P, et al. Interactive versus videobased training of police to communicate syringe legality to people who inject drugs: the shield study, Mexico, 2015-2016. Am J Public Health 2019;109:921-6.

31 Beletsky L, Thomas R, Shumskaya N, et al. Police education as a component of national HIV response: lessons from Kyrgyzstan. Drug Alcohol Depend 2013;132 Suppl 1:S48-52.

32 Tenni B, Carpenter J, Thomson N. Arresting HIV: fostering partnerships between sex workers and police to reduce HIV risk and promote professionalization within policing institutions: a realist review. PLoS One 2015;10:e0134900.

33 Strathdee SA, Arredondo J, Rocha T, et al. A police education programme to integrate occupational safety and HIV prevention: protocol for a modified stepped-wedge study design with paralle prospective cohorts to assess behavioural outcomes. BMJ Open 2015;5:e008958.

34 Beletsky L, Grau LE, White E, et al. Prevalence, characteristics, and predictors of police training initiatives by US SEPS: building an evidence base for structural interventions. Drug Alcohol Depend 2011;119:145-9.

35 Chan DK-C, Hagger MS. Autonomous forms of motivation underpinning injury prevention and rehabilitation among police officers: an application of the trans-contextual model. Motiv Emot 2012;36:349-64.

36 Mittal ML, Beletsky L, Patiño E, et al. Prevalence and correlates of needle-stick injuries among active duty police officers in Tijuana, Mexico. J Int AIDS Soc 2016;19:20874.

37 Beletsky L, Abramovitz D, Arredondo J, et al. Addressing police occupational safety during an opioid crisis: the syringe threat and injury correlates (STIC) score. J Occup Environ Med 2020;62:46-51.

38 Rocha-Jiménez T, Mittal ML, Artamonova I, et al. The role of gender in the health and human rights practices of police: the shield study in Tijuana, Mexico. Health Hum Rights 2019;21:227-38.

39 Poteyeva M, Sun IY. Gender differences in police officers' attitudes: Assessing current empirical evidence. J Crim Justice 2009;37:512-22.

40 Dejong C. Gender differences in officer attitude and behavior. Women Crim Justice 2004;15:1-32.

41 Paoline EA, Myers SM, Worden RE. Police culture, individualism, and community policing: evidence from two police departments. Justice Quarterly 2000;17:575-605.

42 Brooks L, Piquero A, Cronin J. Police officer attitudes concerning their communities and their roles: a comparison of two suburban police departments. Am J Police 1993;12:115.

43 Baker MG, Peckham TK, Seixas NS. Estimating the burden of United States workers exposed to infection or disease: a key factor in containing risk of COVID-19 infection. PLoS One 2020;15:e0232452-e.

44 Kirby T. UK senior police officer with COVID-19. Lancet Respir Med 2020;8:451

45 Manna A, Siddiqui S, Horn P, et al. "Connecting the DOTS: Drug Overdose Trust and Safety"- Implementation of the SHIELD Model to Engage First Responders in Overdose Prevention Implementation Overview 2020 